\title{
Reconstitución \\ epistémica/estética: la aesthesis decolonial una década después
}

\section{Artículo de reflexión}

Recibido: 20 de octubre de 2018

Aprobado: 17 de noviembre de 2018

Cómo citar este artículo: Mignolo, Walter D. (2019). Reconstitución epistémica/estética: la aesthesis decolonial una década después. Calle 14: revista de investigación en el campo del arte 14(25). pp. 14-32. DOI: https://doi.org/10.14483/21450706.14132

\section{(c) (1)}

https://creativecommons.org/licenses/by/4.0/deed.es 



\title{
Resumen
}

Mi argumento conjuga dos instancias decoloniales. La primera es la re-orientación decolonial introducida por Aníbal Quijano (en 1990) en el mero cierre de la Guerra Fría. En los 80s era ya evidente que los objetivos de la descolonización no podrían lograrse por medio de la fundación de Estados nacionales. Quijano intuyó que la colonialidad del poder era un estructura invisible y subyacente de la civilización occidental, oculta bajo las promesas vertidas en nombre de la modernidad. Para Quijano la tarea decolonial era, en primer lugar, desprendernos de la colonialidad del poder y, en segundo lugar, engancharnos en la reconstitución epistemológica. La segunda instancia, 20 años después, fue la introducción de reflexiones decoloniales en el marco de la colonialidad del poder de la restitución estética. En los procesos de avanzar en la reconstitución epistemológica y estética, rescatamos el concepto de aiesthésis del olvido al que la relegó la hegemonía de la estética. Aunque el vocablo proviene de Grecia, nos apropiamos de ella en el marco del pensamiento decolonial. En este ensayo reintroduzco el concepto de gnosis, ya incorporado en Local Histories/Global Designs (2000), para re-organizar los sentidos y la política de la reconstitución epistémica/estética (dos conceptos moderno/coloniales).

\section{Palabras claves}

Gnoseología decolonial; aestésica decolonial; sanación decolonial

\begin{abstract}
My main argument combines two decolonial instances. The first one is the decolonial re-orientation introduced by Aníbal Quijano (in 1990) at the very end of the Cold War. In the 80 s it was already evident that the objectives of decolonization could not be achieved through the founding of national states. Quijano intuited that the coloniality of power was an invisible and underlying structure of Western civilization, hidden under the pledges made in the name of modernity. For Quijano, the decolonial task was, in the first place, to get rid of the coloniality of power and, secondly, to engage in epistemological reconstitution. The second instance, 20 years later, was the introduction of decolonial reflections within the framework of the coloniality of power of aesthetic restitution. In the process of advancing in the epistemological and aesthetic reconstitution, we rescue the concept of aiesthesis from the oblivion to which the hegemony of aesthetics relegated it. Although the word comes from Greece, we appropriate it in the framework of decolonial thinking. In this essay, I reintroduce the concept of gnosis, already incorporated in Local Histories/Global Designs (2000), to re-organize the senses and the politics of epistemic/aesthetic reconstitution (two modern/colonial concepts).
\end{abstract}

\section{Keywords}

Decolonial gnoseology; decolonial aesthesic; decolonial healing

\section{Résumé}

Mon argument principal combine deux instances décoloniales. La première est la réorientation décoloniale introduite par Aníbal Quijano (en 1990) à la fin de la guerre froide. Dans les années 80, il était déjà évident que les objectifs de la décolonisation ne pourraient pas être atteints par la création d'États nationaux. Quijano a eu l'intuition que la colonialité du pouvoir était une structure invisible et sous-jacente de la civilisation occidentale, cachée sous les engagements pris au nom de la modernité. Pour Quijano, la tâche décoloniale consistait avant tout à se débarrasser de 
la colonialité du pouvoir et, deuxièmement, à procéder à une reconstitution épistémologique. Le deuxième cas, 20 ans plus tard, a été l'introduction de réflexions décoloniales dans le cadre de la colonialité du pouvoir de la restitution esthétique. En avançant dans la reconstitution épistémologique et esthétique, nous sauvons le concept d'aiesthesis de l'oubli auquel l'hégémonie de l'esthétique le reléguait. Bien que le mot vienne de Grèce, nous l'approprions dans le cadre de la pensée décoloniale. Dans cet essai, je réintroduit le concept de gnose, déjà intégré dans Local Histories/Global Designs (2000), pour réorganiser les sens et la politique de la reconstitution épistémique/esthétique (deux concepts modernes / coloniaux).

\section{Mots clés}

Gnoseologie décoloniale; esthésique décoloniale; guérison décoloniale

\section{Resumo}

Meu argumento principal combina duas instâncias decoloniais. 0 primeiro é a re-orientação descolonial introduzida por Aníbal Quijano (em 1990) no final da Guerra Fria. Nos anos 80 já era evidente que os objetivos da descolonização não poderiam ser alcançados através da fundação de estados nacionais. Quijano intuiu que a colonialidade do poder era uma estrutura invisível e subjacente da civilização ocidental, escondida sob as promessas feitas em nome da modernidade. Para Quijano, a tarefa descolonial era, em primeiro lugar, livrar-se da colonialidade do poder e, em segundo lugar, envolver-se na reconstituição epistemológica. A segunda instância, 20 anos depois, foi a introdução de reflexões descoloniais no quadro da colonialidade do poder de restituição estética. No processo de avançar na reconstituição epistemológica e estética, resgatamos o conceito de aiestesia do esquecimento a que a hegemonia da estética a relegou. Embora a palavra venha da Grécia, nos apropriamos dela no contexto do pensamento descolonial. Neste ensaio reintroduzo o conceito de gnosis, já incorporado em Local Histories / Global Designs (2000), para reorganizar os sentidos e as políticas de reconstituição epistêmicoestética (dois conceitos modernos / coloniais).

\section{Palavras-chaves}

Gnoseologia descolonial; estética decolonial; cura decolonial

\section{Maillallachiska}

Nukapa rimai nenme iskai luar decolonialkuna. Ñugpa kami uichiringapa decolonial iaikuchiska Anibal Quijanopa (1990- uatapi) chi uichkariska llakichi chirri pusag chunga uatapi (80) ñame kauarikurka chi Iuiaikuna descolonizacionmanda mana allikangapa karkachuchi fundacionkuna estado Nacionalkunaua. Quijanok iuirkame chi colonialidadka sug iuiai mana kauari musu iuiai occidentalmanda. Pakami ianga richispa sug musu Iuiaikuna, Quijanomandak decolonial (karkami ñugpa luar, uarkuringa reconstitucin epistemologicapi. Iskai instanciak iskai chunga uata ialiskaurra (20) kaskami iaikuchiska suma iuirispa decolonialkuna ukupi decolonialmanda chi podermanda. Restitucion estetikamanda, chi proceso suiuchingapa reconstitución epistemológica estetikapi, tandachirisrkami iuiai aestesiskuna kungariskamanda kauachirga chi hegemonía chi estetikamanda. Chi rimai samumi Greciamanda apirirkanchimi paipa ukupi iuiai decolonialmanda.kai ensayopi iaikuchini iuiai gnosispi. Ña llutachisla chi local Histories, Global Designs (2000), tandachispa iuiakuna politikapi chi Reconstitucion Epistemica/ estetikapi, (iskai Iuiaikuna musu, decolonialkuna).

\section{Rimangapa Ministidukuna:}

Gnoseología decolonial; aestésica decolonial; amberei decolonial 
This book evolved accidentally, as a result of an invitation to prepare a survey of African philosophy. Strictly speaking, the notion of African philosophy within the defined framework of the discipline and its historical tradition [...] I have does preferred to speak of African gnosis [...]: to what extent can one speak of an African knowledge, and in what sense? Etymologically, gnosis is related to gnosko, which in the ancient Greek means

"to know."

Specifically, gnosis means seeking to know, inquiry, methods of knowing, investigation, and even acquain-

tance with someone. [...] Gnosis is, consequently, different from doxa or opinion, and, on the other hand, cannot be confused with episteme, understood as both

science and general intellectual configuration (V. Y. Mudimbe, The Invention of Africa. Gnosis, Philosophy and the Order of Knowledge, 1988, ix)

\section{Entramado conceptual}

Reconstitución epistémica involucra desprendernos del par de conceptos: epistémico (adjetivo) y epistemología (sustantivo). Involucra, al mismo tiempo, desprendernos de estético (adjetivo) y estética (sustantivo). Lo estético epistémico alude a cierto tipo de fenómenos relacionados con el saber y el sentir. Epistemología y estética nombran las disciplinas que elaboran, teorizan, investigan tales fenómenos. En la civilización occidental comprobamos que ambos (fenómenos y conocimiento o comprensión de ellos) se separaron a partir del siglo XVIII. La separación se fundó sobre la memoria misma de occidente: la distinción en la filosofía de la antigua Grecia entre metafísica y poética (Aristóteles). Aunque, si recordamos la definición general de filosofía (amor al conocimiento y la sabiduría), ambos, metafísica y poética, eran dos dimensiones del conocer y lo conocido. Mudimbe, recogió del olvido el concepto de gnosis y le dio un nuevo significado. Lo utilizó para nombrar la praxis del pensar en África, borrada por el vocabulario eurocentrado de misioneros, antropólogos, historiadores, periodistas, economistas, politólogos, filosofía, arte, etc. ${ }^{1} \mathrm{O}$ al

1 V. Y. Mudimbe, (1988). The Invention of Africa. Gnosis, Philosophy and the Order of Knowledge. Bloomington: Indiana University Press. En ciencias políticas fue Eric Voegelin quién des-cubrió las huellas del gnosticismo en el pensamiento moderno (Hegel, Marx, Camus). Science, Politics and Gnosticism. (1968). Wilmington: IS Books. Las irreverencias de los pensadores gnósticos son una de las razones para expurgar el vocablo gnosis de las ciencias sociales y humanidades. revés, la filosofía nos es más que un hacer en la memoria y praxis de occidente regulado disciplinariamente, desde la filosofía teológica cristiana, pasando por su secularización durante la Ilustración. Pero la memoria de ese hacer no está en África. La gente piensa, como todo ser humano, y no necesita filosofar, excepto por adopción de haceres que no corresponden con sus memorias. De manera semejante, a partir del siglo XIX, epistemología remite a la teoría del conocimiento científico y filosófico en Europa y en Estados Unidos. James F. Ferrier (filósofo y metafísico escocés, 1808-1864) definió la epistemología por "teoría del conocimiento." Gnoseología prácticamente desapareció del vocabulario relacionado con la teoría del conocimiento. Mudimbe recoge gnoseología de los desechos de occidente para resaltar que los africanos piensan y no les hace falta la filosofía.

Continuando el gesto de Mudimbe, introduje gnoseología en el vocabulario decolonial de Historias Locales/ Diseños Globales (Mignolo, 2003, introducción). La palabra alemana Erkennmistheorie, la expresión francesa théorie de la connaissance y la española teoría del conocimiento fueron traducciones occidentales y modernas de gnoseología. Ferrater Mora [1944] (1984) distinguió en la lengua española teoría del conocimiento de epistemología basándose en el hecho de que la última se remite al conocimiento científico, mientras que la primera alude al conocimiento en general.

A continuación de este párrafo, elaboré en el libro citado la redención del concepto en el argumento de Mudimbe. Nota también Ferrater Mora que la equivalencia entre gnoseología y teoría del conocimiento no es común en el inglés como lo es en alemán, francés, italiano y castellano. Subrayo la diferencia imperial lingüística para retomar gnoseología y desnaturalizar epistemología (reconstitución epistémica) y continúo el uso del vocablo aiesthesis empleado en el artículo publicado en Calle 14. Revista de Investigación en el Campo del Arte, titulado "Aiesthesis decolonial" (2010, pp. 10-25).

\section{Elucidaciones conceptuales}

Muchas aguas han corrido desde la muestra y taller, Estéticas Decoloniales, realizados en Bogotá en noviembre-enero de 2010. Reflexiono sobre ellas a partir del concepto de gnosis que elaboro a partir de la reorientación decolonial en el pensamiento de Aníbal 


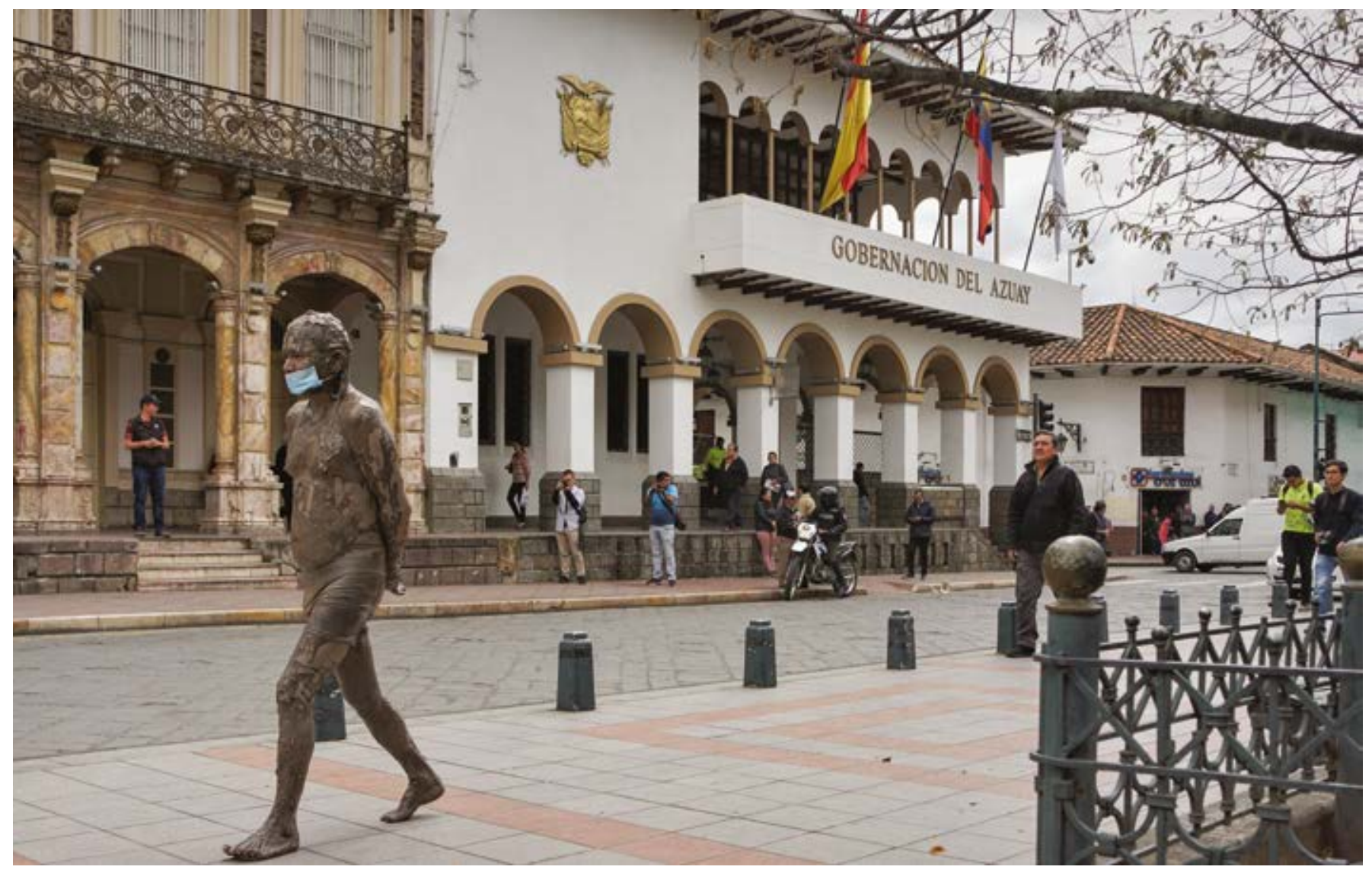

Imagen 1. Hombre de lodo. Performance en Cuenca, Ecuador. Benvenuto Chavajay (2018).

Quijano: la decolonialidad en tanto reconstitución epistemológica. ${ }^{2}$ El parte aguas del evento en Bogotá nos permitió agregar lo estético y al correr de los meses contraponer a lo estético lo aesthésico. De manera que el desprendimiento de lo epistémico/epistemología y estético/estética se funda en la introducción de sus pares imbricados: gnoseología abre la brecha en el primer par y aesthesis en el segundo. Nos queda liberarnos del concepto de "arte" ensamblado con lo estético/ estética. Esto lo haré en el andar del argumento.

La fórmula que emplearé en este ensayo es la siguiente: "reconstitución epistémico/estética" de las esferas del conocer y del sentir en el vocabulario hegemónico moderno/colonial. La reconstitución del contenido y la enunciación de estas esferas (lo enunciado en el vocabulario moderno colonial y la enunciación moderno/ colonial) se efectúa por medio de la introducción de

2 Quijano, Aníbal. (1992). Colonialidad y Modernidad/ Racionalidad. Perú Indígena, 13(29), pp.11-20; Colonialidad del Poder y Clasificación Social. Journal of World-System Research, (2015), 6(2), pp.342-384. Vázquez, Rolando. (2016). Aesthésis Decolonial y los Tiempos Relacionales. Calle 14. Revista de Investigación en el campo del arte, 11(18), pp.76-93. los conceptos de gnoseología y aesthesis. Estos dos conceptos asientan a la vez la enunciación decolonial y reducen epistemología y estética a meros fenómenos investigados, pues la enunciación moderno/colonial deviene contenido para la enunciación decolonial que reemplaza los términos de la conversación. Gnoseología $y$ aesthesis configuran esferas del conocer y del sentir ya no sujetas a epistemología y estética (teoría del fenómeno estético). Estas dos categorías son a la vez analíticas y proyectivas en la medida en que hacen posible construir gnoseología y aesthesis decoloniales. Es decir, reconstitución en la que se entrelaza el imaginario moderno/colonial con el pensamiento fronterizo decolonial.

Ahora bien, al desplazar los vocablos habituales para referirnos al conocimiento y a los fenómenos estéticos, de hecho comenzamos a desplazar los sentidos que los fenómenos mismos adquieren al ser conceptualizados en la epistemología y en la estética. Es decir, la introducción de gnoseología genera una alteración necesaria y abierta hacia horizontes decoloniales desobedientes del efecto universal que le otorgamos a los vocablos regionales tales como epistémico, epistemológico y estético. 
De modo que la reconstitución epistemológica, en la expresión de Quijano, significa a la vez reconstitución de la teoría del conocimiento y de lo conocido en todas las esferas (gnoseológicas y no sólo científicas y filosóficas) y también reconstitución de la (filosofía) estética y de los fenómenos estéticos canonizados. Esto es, la historia del "arte" en el archivo de Europa y de Anglo-América, ya no es relevante para la reconstitución aesthesica de la estética sino en la medida en que permite destacar la diferencia colonial entre la estética y la aesthesis. Con ello quiero subrayar que al argumentar de esta manera establecemos una distancia entre la reflexión decolonial en torno a fenómenos que han sido codificados en el vocabulario moderno/colonial y prolongados en el vocabulario posmoderno/postcolonial.

Un par de aclaraciones más en torno a confusiones que surgen a menudo al hablar o escribir sobre estos temas. La expresión de Quijano es "patrón colonial de poder" (PCP). "Patrón" es derivado de la terminología latina, variada pero que en el fondo tiene la figura del padre y de quien ordena. En ese sentido "patrón" es pertinente y va de la mano con el feminismo comunitario (FC), una teoría social surgida de las experiencias andinas (aymaras en este caso) que confronta el patriarcado no ya como una cuestión de género sino como una cuestión de dominación y control en todas las esferas del existir. En la traducción al inglés "patrón" se tradujo por "matrix" y de vuelta al castellano resultó en "matriz". Matriz tiene dos sentidos relevantes a su denominación: el más antiguo significado es el de útero, en el sentido general de lugar donde se gesta y regeneran los organismos vivientes. Más recientemente, a principios del siglo XX, comenzó a usarse en sentido lógico: una gama de posibles combinaciones de valores de "verdad". El film The Matrix, toma este segundo sentido. Creo que el título no se tradujo para la exhibición del film en España y en Hispanoamérica.

Por lo tanto, matriz colonial del poder (MCP), derivado de Quijano, y feminismo comunitario (FC), en la versión de Julieta Paredes, marchan por sendas paralelas en una misma dirección, pero provienen de memorias, historias, sentires y saberes diferentes. Es decir, ambos proyectos se nutren de distintas energías alimentadas por las diferencias implantadas por la clasificación social moderno/colonial. La diferencia colonial instituye heridas coloniales que disminuyen a la persona, pero generan a la vez digna rabia que nutre la necesidad de sanaciones decoloniales. Sin sanación decolonial, las personas quedan atrapadas en el resentimiento y el resentimiento impide la liberación, la autoafirmación, la dignificación, que son procesos de sanación decolonial. ${ }^{3}$

Para que esto sea posible es necesario que las subjetividades involucradas en la formulación de estas propuestas estén ya desenganchadas de las expectativas institucionales que gestionan y controlan el conocimiento: tanto lo conocido, lo que sabemos, como los modos y principios que regulan el conocer y el conocimiento. La reconstitución epistemológica, derivada de Quijano, y la teoría social del patriarcado propuesta por Julieta Paredes, no podrían haber sido formuladas sin un desplazamiento gnoseológico/aesthésico de las modulaciones moderno/coloniales de subjetividades aesthésicamente obedientes.

Para quienes han llegado hasta este punto advierto que lo que acaban de leer no es análisis (e.g. estudio) ni argumento explicativo "de" la decolonialidad, sino que es praxis decolonial haciéndose: pensamiento decolonial en el hacerse y constituirse en sí mismo. Por eso "estudios decoloniales" no es reflexión decolonial, sino apropiación moderna (o postmoderna) de la praxis decolonial. Todo aquello que el vocabulario moderno y postmoderno nombra y describe que no es su propio hacer ni tampoco la memoria de occidente, no se identifica con lo descrito y lo nombrado. Del silencio impuesto por la epistemología y la estética surgen las energías decoloniales gnoseológicas y aesthesicas. En su hacerse y constituirse en su misma praxis, pensar decolonialmente es un constante desprendimiento (delinking) de la epistemología moderno/colonial y un constante hacer gnoseológico/aesthésico. El hacer gnoseológico presupone la epistemología de la cual se desprende. Por lo tanto, está enganchado con ella en un constante diferencial de poder, el diferencial de poder constituido por la matriz colonial del poder, MCP.

Cómo nos desprendemos, si es lo que queremos, de la MCP, es una pregunta habitual. Haciéndolo es la respuesta más simple. Hacerlo implica comenzar por el vocabulario que nos atrapa y nos ata en el pensar y en el sentir que el vocabulario controla. Pero no nos damos cuenta de ello hasta que comenzamos a interrogar no lo que las cosas son sino cómo llegaron a ser lo que

3 Cabnal, Lorena (2016). "Red de sanadoras ancestrales", en «https://luchadoras.mx/lorena-cabnal-sanacion/»: Santiago, Karen (2016). "Lorena Cabnal, Sanación, feminismo y defensa comunitaria." Luchadoras, en «https://luchadoras.mx/lorena-cabnal-sanacion/» Chavajay, Benvenuto. Muxu'x, la habilidad de hacer cosas (arte) para sanar la herida colonial (ver análisis y referencias en las páginas siguientes). 
son; no preguntamos ya qué son la epistemología y la estética, sino cómo llegaron a ser lo que son; no lo qué es el arte sino cómo llegó a ser lo que es. Estos son los temas centrales de este ensayo. De ahí la sobreposición de gnoseología a epistemología, de aesthesis sobre estética.

Otro punto por aclarar: reemplazar los términos de la conversación en vez de los contenidos. "Cambio" es un mantra en la retórica de la modernidad. Se celebra la "novedad" y el "cambio" pues sin cambio no habría novedad. Estos cambios son siempre en los contenidos, no en los términos de la conversación controlada por la enunciación de la MCP, que es su núcleo. El momento radical para entender el significado y la importancia entre términos (reglas, principios) de la conversación, lo constituye el comienzo del siglo XVI en las imágenes, los mapas, los relatos, las descripciones, de misioneros, soldados y letrados (así se llamaban en el Renacimiento quienes fueron reemplazados por los intelectuales hacia finales del siglo XVI en Europa) que acapararon e impusieron su limitado entender y su amplia ignorancia. La imprenta estuvo a su favor para imponer opiniones vertidas como verdades.

Para los castellanos y luego para el resto de Europa, la Conquista y colonización fueron un cambio en los contenidos de la conversación, contenidos que habían sido forjados en la Edad Media y en el temprano renacimiento. Para los conquistadores, comerciantes, guerreros y misioneros de Iberia primero y del resto de Europa occidental luego, no fue necesario cambiar los términos de la conversación. Para nosotros, cambiar los términos de la conversación significa remover, reemplazar des-universalizar los conceptos claves como epistemología, estética, democracia, filosofía, ciencia, estado, capitalismo identificado con economía. A su vez, para los Pueblos Originarios y los seres humanos esclavizados en África, fue un vuelco radical en sus propios términos de la conversación. Sus memorias, lenguas, vida cotidiana, organización política y económica, conocimiento y haceres que en el vocabulario occidental devinieron arte, drama, música, otros, fueron fracturadas y sus praxis de vida debieron cambiar los términos de la conversación. Se encontraron de pronto habitando la frontera entre sus memorias y lenguas y las del invasor y la de los comerciantes de esclavizados. Todas las esferas del vivir fracturadas se alteraron y generaron praxis de vida alteradas. De esa energía surgieron proyectos que hoy podemos entender decolonialmente. No fueron solo proyectos de oposición y resistencia sino de preservar y re-existir frente a la emergente colonialidad del poder. Toda la historia silenciada de energías decoIoniales es lo que exige la reconstitución gnoseológica de la epistemología y aesthésica de la estética. epistemológica/gnoseológica y estética/aesthésica. ${ }^{4}$

El pensamiento fronterizo surge de la "/" que divide y separa epistemología de gnoseología y estética de aesthesis. La reconstitución epistemológica tiene que ser a la vez gnoseológica y aesthésica afincada en las lenguas, memorias, costumbres devaluadas por su barbarie, por ser primitivos, por su tradición, por su paganismo, no puede sino comenzar por allí. Por eso, habitar las fronteras (no por elección sino por colonización) hace que el pensar y hacer fronterizo, en su posibilidad gnoseológica y aesthesica, sea hoy el terreno donde se juegan las alteraciones en los términos de la conversación. Sin embargo, quienes nacimos y fuimos educados en el ámbito de la civilización occidental sin más, habitamos fronteras en su interioridad. Interioridad que no es óntica sino epistémica: es una construcción en los saberes europeos (no asiáticos, ni africanos). En cambio, quien fue nacido y educado en memorias y praxis de vida ajenas a occidente, al ser escolarizado en los modos de conocer, de pensar, de creer no-occidentales habita fronteras trazadas por memorias y lenguas cuyas trayectorias no se intersectan hasta la expansión de occidente a lo largo de cuatro siglos (1500-1900): el mandarín, las lenguas urdu e hindú en India, el árabe en Egipto y en Argelia junto a la lengua berber, experimentaron su propio Pachakuty en la expansión occidental liderada por Inglaterra y Francia. Cuando se habita la frontera no importa que orientación política, escuela filosófica, tendencia artística o teoría científica se adopte, la fronterización del pensamiento está siempre ahí: o se la reprime para conformarse o se estalla para el desprendimiento y la liberación.

Para quienes descendemos de poblaciones europeas (seamos ibéricos en América del Sur, anglos en EE. UU, Australia y Nueva Zelandia o afrikaans en África del Sur) habitamos las fronteras en la interioridad de la civilización occidental, no en las fronteras de la MCP. Pero no todas las fronteras tienen el mismo "valor." Las fronteras en la que habitamos en América Central y del Sur, son las fronteras entre el desarrollo y el subdesarrollo, entre el Primer y el Tercer Mundo; habitamos también las fronteras entre, por un lado, la lengua alemana, francesa e inglesa y por otro, la del castellano y el

4 Sobre este punto consultar el argumento de Pedro Pablo Gómez. (2015). Estéticas fronterizas: Diferencia colonial y opción estética decolonial. Bogotá: Universidad Distrital Francisco Caldas. 


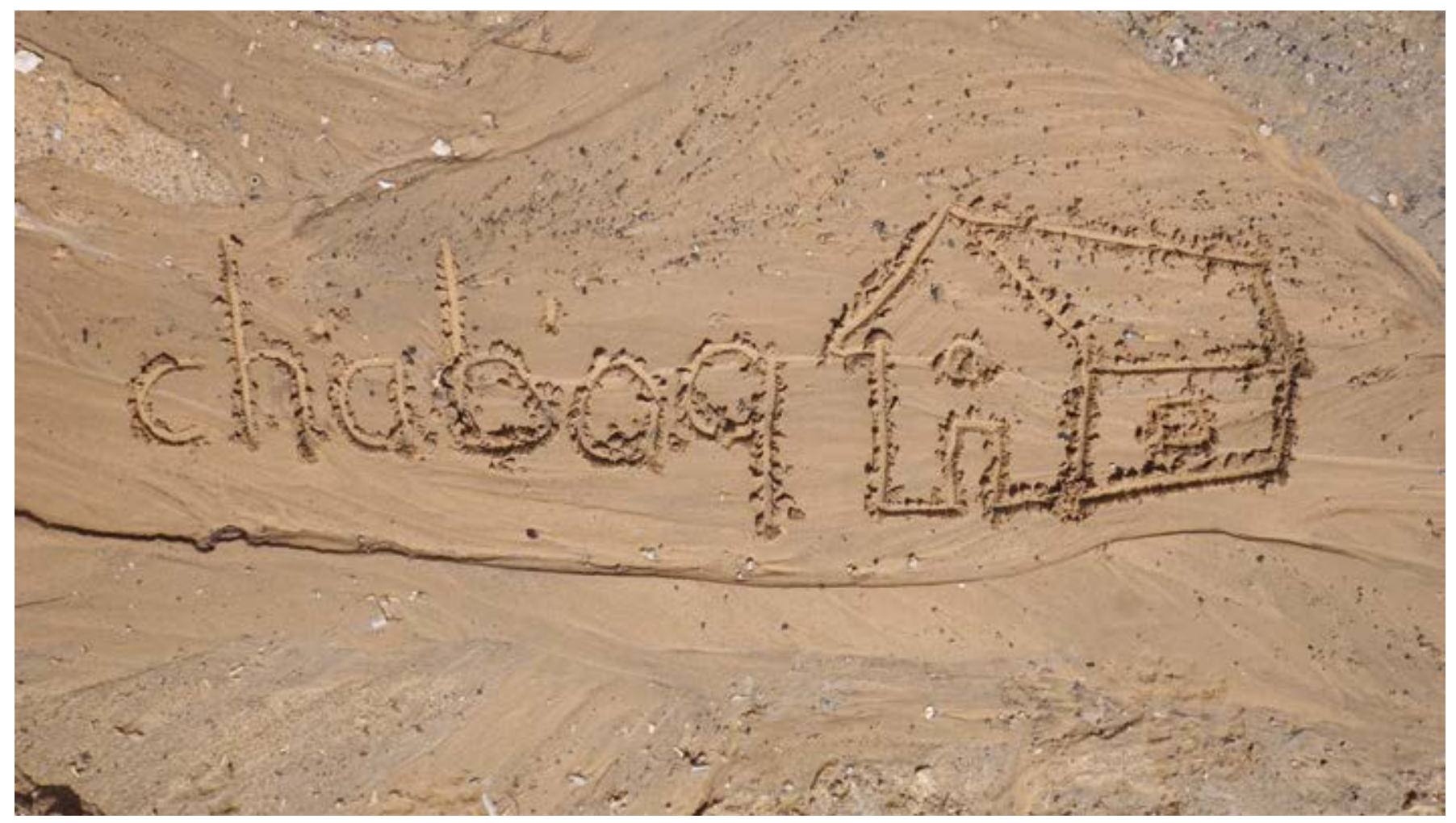

Imagen 2. Ch'ab’aq Jaay. Escritura en el charco de lodo. Benvenuto Chavajay (2018).

portugués. De modo que los márgenes de la civilización occidental no tienen el mismo "valor" para descendientes de ingleses en Nueva Zelanda y en Australia (clasificadas en la Cristiandad Occidental por Samuel Huntington), que en Bolivia, Argentina o Colombia (clasificadas en América Latina, desde México la frontera norte de México hacia el Sur). ${ }^{5}$ En otro nivel, lo mismo ocurre en Europa: el Sur de Europa perdió el tren de la modernidad en el Siglo XVIII y eso se nota hoy en la configuración de la Unión Europea. En fin, podría continuar esbozando las fronteras más complejas entre Europa del Oeste y Europa del Este.

Lo que argumento con estos ejemplos no es una historia y etnografía de la constitución de fronteras en la formación y trasformación de la MCP. Lo que intento subrayar es que la reconstitución gnoseológico/aesthésica no puede sino fundarse en la interioridad de las fronteras de la MCP y también en su exterioridad (el afuera inventado y necesario para la constitución del adentro) puesto que es en la frontera de la exterioridad donde se siente (aesthesis) la herida colonial y la respuesta involucra rehacerse conociendo (gnoseología).

5 Ver mapa aquí: «https://image.slidesharecdn.com/ guerrafra-100930183904-phpapp01/95/guerra-fra-75-728. jpg?cb=1285872140»
El momento de la reconstitución gnoseológico/aesthésica de la epistemología y de la estética es similar al de la Facultad, en el vocabulario de Gloria Anzaldúa. ${ }^{6}$

\section{Hacer (pensando y con las manos) para sanar la herida colonial}

Cuando escuchamos a Benvenuto Chavajay en el video Muxu'x o vemos el catálogo de la exposición Muxu'x: of Origine and Disobedience, (2015) nos encontramos con un caudal de haceres (objetos creados) y decires (la articulación de su hacer), en los que se entroncan la praxis del vivir, con la praxis del pensar y la praxis del hacer. En el video nos encontramos con algunas ideas fundamentales de la reconstitución epistemológica que es a la vez gnoseológica y aesthesis.

$6 \quad$ Gloria Anzaldúa sienta una dimensión del conocer que llama la facultad. El paralelo con la gnosis no debemos pasarlo por alto: "La facultad is the capacity to see in surface phenomena de meaning of deeper realities, to see the deep structure below the surface. It is an instant "sensing", a quick perception arrived without conscious reasoning." Borderland/La Frontera. The New Mestiza. (1987). San Francisco: Aunt Lute, Books, p. 62. 


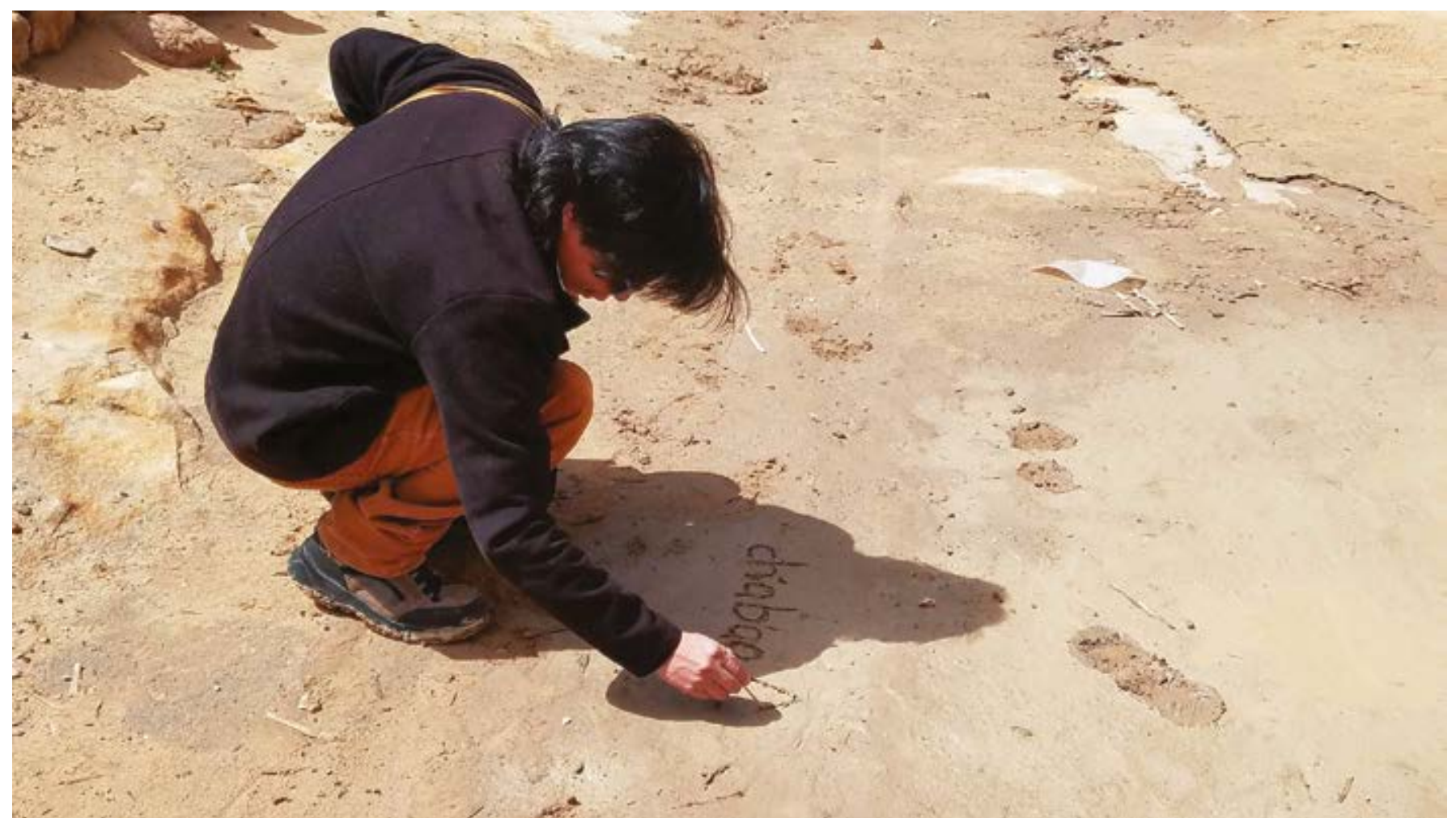

Imagen 3. Escribiendo su apellido en un charco de lodo. Acoma, pueblo en reserva en Nuevo Mexico, Estados Undos. Benvenuto Chavajay (2017).

Al comienzo de la entrevista Chavajay habla de la aesthesis (habla de su sentir, de su aesthesis, aunque no use la palabra), del habitar la frontera entre la ciudad donde vive, Guatemala y su pueblo natal, San Pedro de la Laguna; de su proveniencia de lengua, de familia y de lo comunal maya y de su experiencia en la ciudad de Guatemala. Habitar la frontera le lleva a sentir (aesthesis) que al regresar a su pueblo ha "perdido las miradas." Eso lo lleva a lidiar con esa situación y lo hace por medio del "arte y la estética" (sus propias palabras en este momento de la entrevista). No obstante, hacia el final del video se enfrenta al concepto mismo de "arte". En la lengua maya no hay una palabra equivalente, nos dice Chavajay. "Siente" (la aesthesis en este caso se manifiesta en la esfera cultural ladina y ciudadana en el vocablo "arte") que su hacer (poiesis) es "atrapado" en la esfera léxica y conceptual de "arte".

En la cultura, memoria y vivir maya —nos dice Chavajay- lo que él hace pertenece a la esfera de lo sagrado y de la espiritualidad comunal, no del arte. Chavajay describe su hacer como un hacer necesario para la sanación. Chavajay remueve y reemplaza el concepto de arte y por consiguiente de estética que en occidente van de la mano, por el "hacer" en la esfera de lo sagrado y la espiritualidad. Se desprende así de las variadas conceptualizaciones que "arte" a partir del siglo XIX adquiere en el vocabulario moderno/colonial. En el vocabulario de la estética, para Tolstoy el arte era "expresión" y para Dewey es "experiencia". 7 Para Chavajay en el vocabulario decolonial es "sanación". Hay una brecha entre los dos primeros y el segundo: esa brecha es la diferencia colonial en la que Chavajay se afirma sin arrepentimiento y sin disculpas; al contrario, con orgullo.

En ese momento de su decir (en el video Muxu'x) Chavajay recurre al tema del "alejarse" (desprenderse) de la cultura y el vocabulario que nombra algo que ya ni le pertenece ni le interesa: el archivo occidental del arte. "Siente" la opresión subjetiva, conceptual de occidente del cual busca alejarse, limpiarse, sacarse el polvo, desprenderse. Llega al punto de despreocuparse de si su hacer es "arte" según los criterios provinciales de occidente, tampoco necesita ya alimentarse de "artistas" franceses o estadounidenses. Lo que hace (poiesis, ars: habilidad para hacer algo) lo hace para alejarse de occidente y sanar la herida colonial instaurada por la diferencia colonial. Su hacer está impregnado de memorias, palabras, sensaciones, ruidos, colores (en fin, impregnado por la aestésis de sus ancestros) impuestos 
por el acoso y hostigamiento de occidente instalado en la cultura oficial-nacional de Guatemala.

Y es aquí que Chavajay modula una propuesta que sobrepasa su propio hacer e irradia energía que infiltra la enunciación de MCP (como un virus) irrumpe e interrumpe las tranquilas aguas hasta donde habitan la epistemología y la estética. Chavajay remueve y reemplaza los términos de la conversación controlados por y en la enunciación de la MCP. Sus enunciados (frases, vocabulario, metáforas, vocablos maya) conectan lo que hace con sus manos con la extensión de las manos (los instrumentos que usa) con la reflexión de lo que hace, por qué lo hace y para qué lo hace. Podemos imaginar que en el organismo biológico-cultural identificado legalmente "Benvenuto Chavajay" se inscribe una experiencia local que es al mismo tiempo global: el conocimiento de los cuerpos biológico-culturales que habitan-en distintas latitudes y longitudes del planeta- las fronteras (diferencia colonial) trazadas en la construcción de la exterioridad de la MCP. Fronteras (geográficas, raciales, sexuales, lingüísticas, filosóficas, entre otras) que inscriben la diferencia colonial, por lo tanto, la herida colonial, donde se generan procesos de sanación en todas las praxis del vivir. ${ }^{8}$

La sanación decolonial abarca todas las esferas porque las heridas coloniales emplazadas por la MCP no fueron colocadas únicamente en la esfera del arte y la estética, sino en todas las esferas de la colonialidad del vivir y del saber. Y, dado que el control de subjetividades, la administración de heridas coloniales es en últimas una cuestión epistémica/epistemológica, la epistemología incluye la teorías estéticas y del arte. La administración de heridas coloniales abarca desde las experiencias cotidianas hasta las esferas disciplinarias, que se insertan en las políticas estatales y en las instituciones económicas, en las creencias y -en fin- en todo el ámbito del vivir. De modo que lo que estoy diciendo en este momento, mis observaciones sobre Chavajay, no las ofrezco como una descripción académica o intelectual de su "obra" y de su "teoría" sino que estoy aprendiendo de él a "sacarme el polvo" de occidente aunque para mí sea más difícil la tarea porque no tengo, como él, un pueblo en el que habitan sus coetáneos mayas anclados en la memorias y en las lenguas de sus ancestros. Nuestros desprendimientos (quienes no

8 Ver Marcial Godoy-Anativia (2024). Desobediencia Visual: Una entrevista con Benvenuto Chavajay y Kencey Cornejo. E-misférica 11.1., en «http://hemisphericinstitute.org/hemi/en/ emisferica-111-decolonial-gesture/cornejochavajay» somos en América ni Pueblos Originarios ni descendientes de la diáspora africana donde encontramos experiencias semejantes a las de Chavajay como las de Manuel Zapata Olivella, Edouard Glissant), está anclado en nuestros ancestros europeos (inmigrantes) o mestizo/as cuyos glóbulos rojos muestran en el microscopio sangre indígena o color de la piel pero cuya memorias, lengua, educación y en fin, su aesthesis, evidencia un mestizaje escolarizado en las márgenes de la cultura europea sobre las indígenas y afro-descendientes.

Mestizas/mestizos e inmigrantes (no-indígenas ni afro-descendientes), en las Américas y el Caribe, tenemos -por un lado- el privilegio de nuestra descendencia europea (mestizxs o nacidos y educados en familias de inmigrantes) fuimos escolarizadxs en la historia, valores y pensamiento cristiano/occidental y -por otro- el inconveniente de nuestros privilegios de euro-descendientes en un continente habitado por Pueblos Originarios y afrodescendientes. $Y$ en el orden global, nos encontramos en el menoscabo de habitar países subdesarrollados del (ex) Tercer Mundo. De modo que nuestras (en el sentido en que lo acabo de exponer) afirmaciones, nuestras resurgencias, la sanación de nuestras heridas coloniales opera en la fronteras del privilegio europeizante de la euro-descendencia en América frente a los Pueblos Originarios y afrodescendientes y, por otro, en el menoscabo-en el orden global--de no ser sino "descendientes de". ${ }^{9}$ Ser Sudakas en Europa e Hispánicxs o Latinxs en Estados Unidos. El emocionar que motiva el pensar surge de las clasificaciones que se nos asignan en la MCP.

Las clasificaciones crean nuestras identidades "tercermundistas" o "del Sur global" que podemos reivindicar políticamente, lo cual no borra el hecho de que la clasificación (Tercer Mundo o Sur global) nos ha sido impuesta. Por eso la nuestra (en el sentido en que acabo de explicar), es una tarea de reconstitución gnoseológica de lo epistémico (tanto de lo conocido como del modo y principios del conocer) y aesthésica de lo estético (regulación del gusto y consagración del genio del hacedor). Las búsquedas de los caminos para desprendernos (sacarnos el polvo de encima, Chavajay dixit) nos puede llevar (y este fue mi caso) al encuentro de Rodolfo Kusch. Su obra, leída gnoseológicamente, es una batalla permanente en busca de la "América Profunda" cubierta por el polvo de occidente. Pero esa

9 No entro aquí en el tema del mestizaje que, en general, la mezcla de sangre disfraza la mentalidad europeizante. Ver al respeto, Sanjinés, Javier. (2005). El espejismo del mestizaje. La Paz: IFEA. 
"América Profunda" ya no es, no puede ser, aquello que era y había antes de la conquista, por el simple hecho de que antes de 1504 no había "América." Esa batalla es racional (filosófica) anclada en la aesthesis del no querer ser, que el imaginario moderno demanda, y admirar el estar siendo de las praxis indígenas y afro-descendientes del vivir.

Quitemos el adjetivo "profunda" que puede dar pie a sospechas. Digamos que por "profunda" queremos decir la América que se configuró, desde el siglo XVI, sobre tres grupos demográficos diversos, muy diversos, pero con mucho en común que liga a los grupos en la diversidad: los Pueblos Originarios desde los Mapuches a las Primeras Naciones de Canadá; los pueblos europeos llegados sin invitación y sin pasaportes, se instalaron y controlaron el gobierno, la economía, la cultura y dejaron este legado a sus descendientes y, finalmente, la diáspora Africana forzada a habitar América. América Profunda fue constituida y llega hasta nosotros, por y en las fronteras de estos tres grandes grupos demográficos, y con el privilegio de la población de descendencia europea.
No son solo cierto tipo de haceres entrampados en la palabra "arte', de la cual se desprende Chavajay, lo que nos ata sino nos ata también los haceres entrampados en la palabra "teoría" o "interpretación." Desprendernos de ellos no requiere "nuevas definiciones" (puesto que mantendríamos las reglas del juego, sin cuestionarlas) sino desprendernos de los vocablos investigando no lo que dicen que es (arte, teoría, interpretación) sino cómo lo que es llegó a ser: estrategia metódica radical del pensar y hacer decolonial.

En América del Sur se nos hace sentir a través de la MCP (y específicamente desde la conquista a las poblaciones indígenas y africanas, y desde el siglo XVIII a las poblaciones criollas y mestizas en las obras de Buffón y de Hegel) las deficiencias de las Américas que no sea US, puesto que Hegel ya le había asignado a la América anglo-sajona el puesto el papel de heredera de Europa. Es así que la reconstitución gnoseológica y aesthésica sea siempre de sanación conceptual y subjetiva. Repito: no es teorizar la sanación, sino sanarse en el proceso de desprendimiento de lo epistémico y lo estético en su doble faz: por un lado el archivo

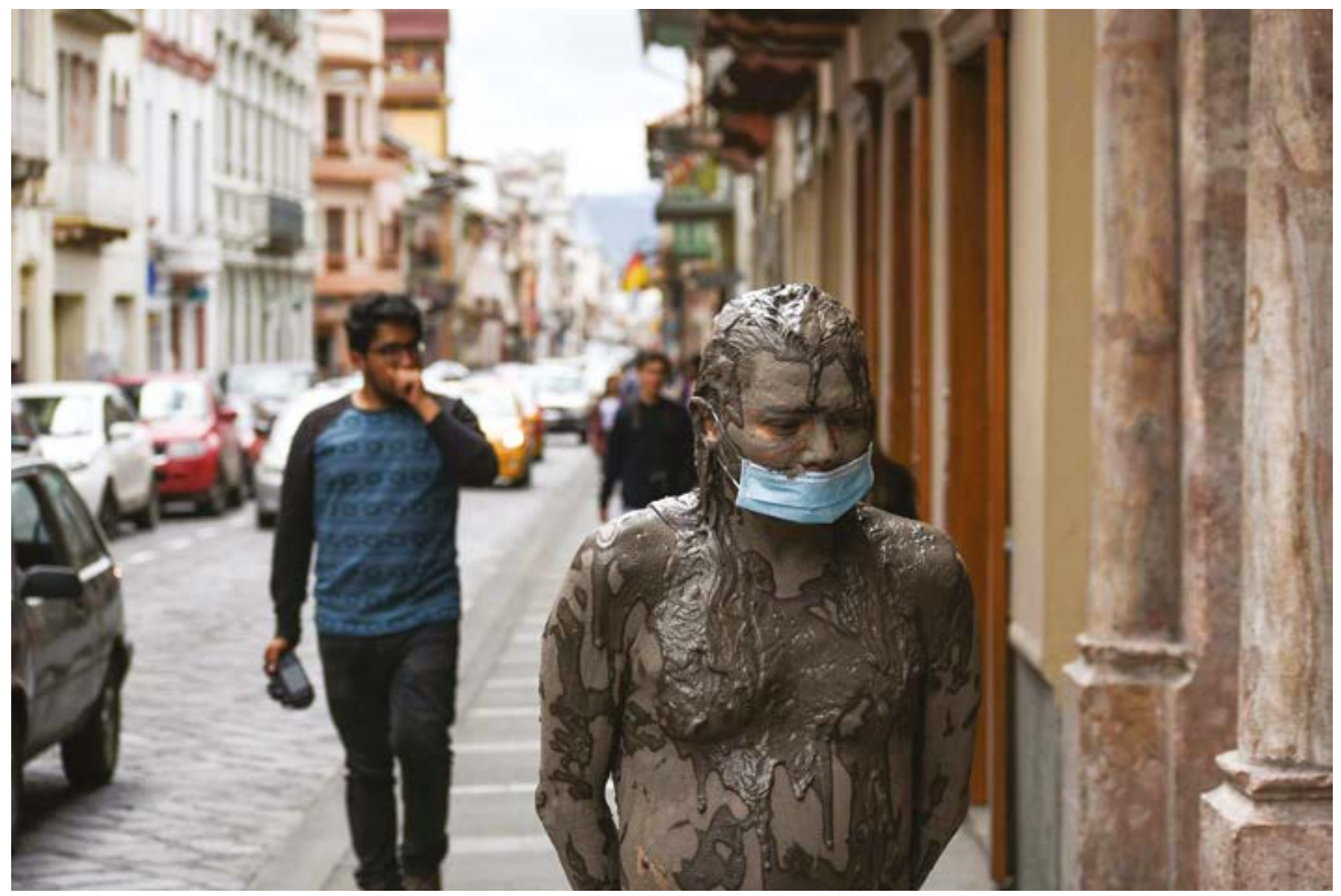

Imagen 1. Hombre de lodo. Performance en Cuenca, Ecuador. Benvenuto Chavajay (2018). 


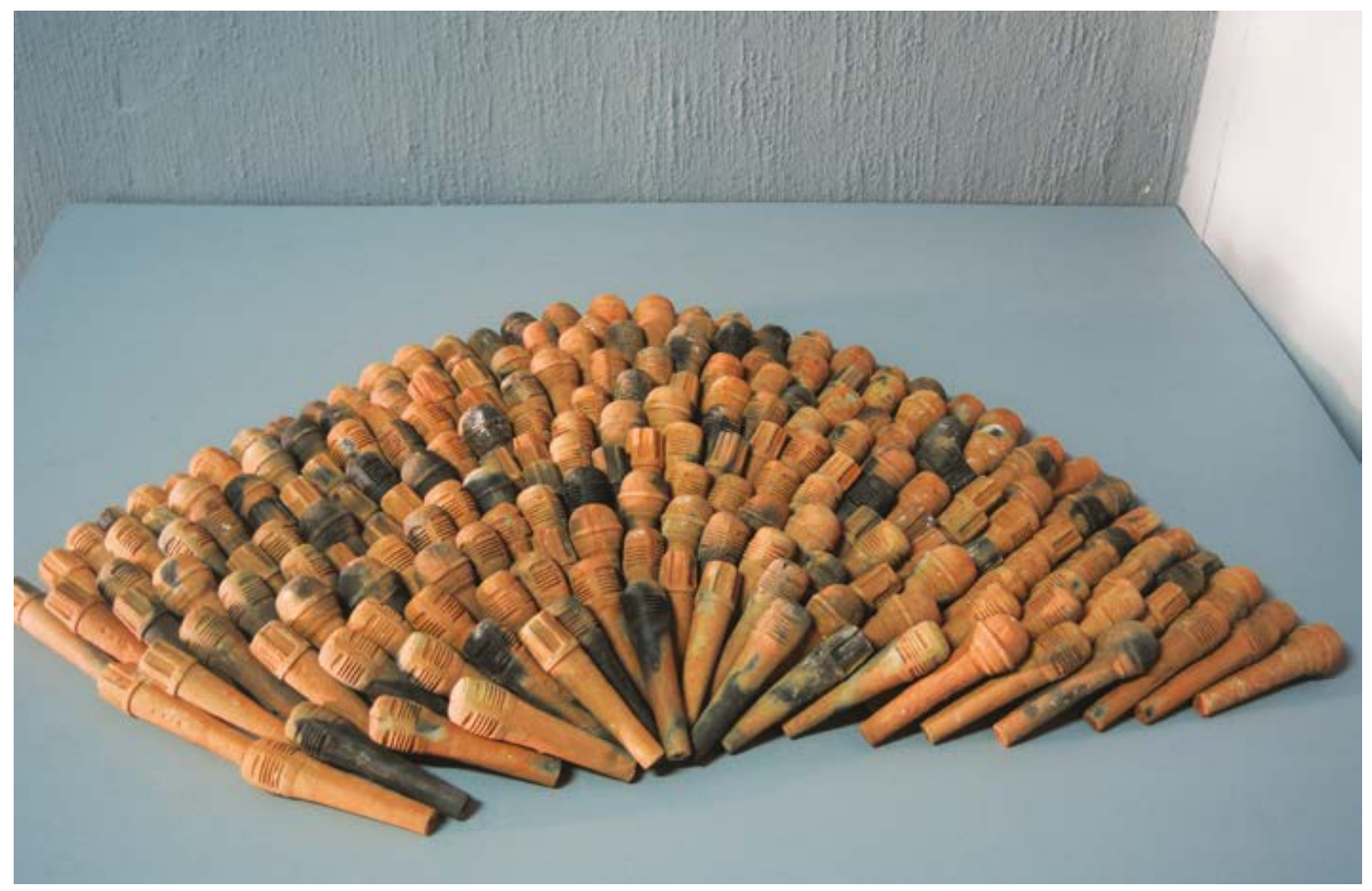

Imagen 5. Micrófonos de barro. Benvenuto Chavajay (2014).

(conocimiento), objetos o actuaciones y, por otro, regulaciones para conocer lo conocido y estetizado.

\section{Los vocablos modernos (postmodernos)/coloniales nos atrapan}

Decimos a menudo -en conversaciones con quienes compartimos ideas, preocupaciones y vínculos decoloniales- que "descolonizar la estética significa liberar la aesthesis." Al escuchar a Chavajay y revisar el catálogo de la exposición Muxu'x, nos encontramos con la encarnación de la fórmula. $O$ al revés, el video y el catálogo evidencian que la descolonización de la estética es necesaria para liberar la aestésis. Es decir, nos embarca en la reconstitución gnoseolósica y aesthesis de la epistemología y de la estética (que conlleva el concepto de arte) y en las sendas de la sanación. Nos afirma en nuestros haceres y saberes de espalda a la MCP. No necesitamos ya de modelos occidentales, nos dice Chavajay en el video. Pero insistamos, no solo en la esfera de las artes el desenganche es necesario para el camino de la sanación. Es en toda la esfera gnoseológica colonizada por la ciencia y la filosofía seculares.
Descolonizar la estética requiere desacoplar la estética del "arte" (en el sentido limitado que adquirió la expresión después del siglo XVIII) e incorporar la aesthesis oculta en la estética y hecha su prisionera, a todos los haceres en los que opera la MCP. La aesthesis subyace a la ciencia y la filosofía: subyace a la ciencia, la filosofía y la epistemología; subyace a la teoría política y la economía política. Por eso Adam Smith, antes de escribir La riqueza de las naciones (1776) publicó Una teoría de los sentimientos (1748). Lo cual nos alerta en que La riqueza no es una obra de economía política sino de teoría moral. Pero en ese momento, la moral no estaba conectada con la estética en el vocabulario moderno/colonial. De modo que la aaesthesis no es un privilegio decolonial sino que es consubstancial con los organismos vivientes y sintientes, pero fue suprimida en la teología y en la filosofía y ciencias seculares en beneficio de la razón teológica y la razón filosófica y científica. Lo aestésico nos impregna, está en todo lo que hacemos. Liberar la aesthesis de la estética des-cubre la geopolítica del sentir, pensar, hacer, creer y la extrae también del imaginario abstracto del sujeto moderno, despegado de las energías geopolíticas gestionadas por la MCP. Nos lleva a descolonizar el concepto 
cristiano/liberal (porque de estos temas quienes sostienen ideas liberales no hablan) de "amor" liberándolo de la "cultura" (lo hecho por los seres humanos) para situarlo en la praxis vivencial de nuestros organismos celulares (cuerpos se dice también, no hechos por los seres humanos aunque no sepamos por qué o quién): el "amor" es el vocablo que describe las tendencias de los organismos vivos a con-vivir con lo viviente (no solo seres humanos), interrumpidas (pero no anuladas) por la "cultura" competitiva, guerrera y patriarcal.

La aesthesis subyace y con-forma la epistemología y la estética moderno/coloniales. Es decir, la epistemología y la estética son impensables sin la aesthesis que nutrió a los actores fundadores, sostenedores y propagadores de ambas. $O$ al revés, la estética y la epistemología ocultaron la geopolítica aesthésica que las generó.

Puesto que epistemología y estética no surgieron ni en Bolivia, ni en Namibia, ni en Indonesia ni en las primeras naciones en lo que es hoy Colombia. Lo cual, no quiere decir que la gente de esos lugares no pensara ni fuera creativa en sus haceres (arte: habilidad para hacer algo). Quiere decir que conceptualizaba de otras maneras sus haceres; y aquella gente tampoco alimentaba tareas misionales de conversión de otras comunidades. De ahí la expresión de Quijano "colonialidad y modernidad/racionalidad." No habría epistemología si la aesthesis (las vibraciones de los órganos sensoriales) no hubiera propulsado a los organismos humanos vivientes a reflexionar sobre su propia actividad de pensar. Los argumentos de esta reflexión que usted está leyendo, siguen las reglas racionales de la argumentación, que no los motiva la razón sino la aesthesis que es siempre, aun el las ciencias naturales, irracional y motivante. Los resultados de la ciencia, la filosofía y las teorías del conocimiento son resultados racionales: pero los principios y presupuestos que provoca un tipo de conocimiento u otro, son irracionales. Las "obras de arte" en sus variadas manifestaciones producen el objeto y el efecto estético. Sin embargo, el impulso que las motiva es aesthésico, así como es aesthesis las respuestas de Ixs espectadores o las audiencias en su indiferencia o atracción por tales objetos 0 actuaciones teatrales 0 musicales. Ahora bien, mientras que lo aesthésico es biológicamente universal en los organismos vivientes, no lo es culturalmente. Culturalmente lo aesthésico está geopolíticamente con-formado por la colonialidad del poder y las clasificaciones sociales que sitúan y confrontan los seres humanos compitiendo y jerarquizando el sentir, saber, pensar, creer.

\section{El origen de la originación}

Las jornadas en torno a "Estéticas decoloniales: sentir, pensar y hacer en Abya Yala y la Gran Comarca" en Bogotá en noviembre-diciembre del 2010 pusieron la pica en Flandes y atendieron a la pregunta soslayada en torno al lugar del arte y la estética en la MCP. ${ }^{10}$ Fue el signo visible del proceso de quita y reemplazo radical en los términos de la conversación y no ya en el contenido. Participaron "artistos" (al decir de Chavajay) de las primeras naciones y afrodescendientes, pero la muestra fue organizada por eurodescendientes. Mientras que Benjamín Jacanamijoy Tisoy, al preguntarle por la traducción del concepto "colonialidad" al kichwa, nos dijo después de reflexionar unos minutos: "memoria robada".11

El evento fue un primer esfuerzo "nuestro" (quienes organizamos y participamos: y quienes pensamos decolonialmente a partir de la colonialidad del poder) por quitar y reemplazar los términos de la conversación. La decolonialidad no funciona por golpe de "estados" (cualquier "estado" de cosas), sino por procesos de larga duración, lentos, contradictorios, ambiguos. Pero lo que no se pierde es el horizonte y la aesthesis que los motiva y alimenta ${ }^{12}$. Para allá vamos, y al andar vamos rehaciéndonos, quienes somos, con quienes andamos y con quienes ya no; marchamos desenganchándonos de la telaraña conceptual de la MCP que encontramos a cada paso -en el arte, la estética, la epistemología, la política, la economía, la religión-.

Exploremos un poco más esta fórmula puesto que es clave para conceptualizar y actuar en la decolonialidad del "hacer" y del "pensar haciendo" (puesto que pensar lo hacemos siempre, y la mayoría del tiempo sin darnos cuenta que pensamos) que en términos de los contenidos modernos/coloniales sería arte y estética y en

10 El catálogo de la exposición se encuentra en Pedro Pablo Gómez y Walter D. Mignolo. (Eds.). (2012). Estéticas decoloniales. Bogotá: Universidad Distrital Francisco José de Caldas. La publicación de algunas ponencias del taller se encuentra en Walter D Mignolo y Pedro Pablo Gómez. (Eds.). Estéticas y opción decolonial. Bogotá: Universidad Distrital Francisco José de Caldas. Varias publicaciones, exhibiciones y talleres siguieron desde entonces en Canadá, Cuba, Estados Unidos, Berlín, Middelburg. La trayectoria desde entonces hasta aquí alimentó su continuación en este ensayo.

11 Originario de Manoy Santiago, Colombia, «http://www.arteyconexion.com/directorio-de-artistas/benjamin-jacanamijoy-tisoy/» 12 Las jornadas de Bogotá se continuaron en Duke en 2011 (https://today.duke.edu/2011/05/decolonial). Y en 2012 Alanna Lockward comenzó las jornadas de Be-Bop en 2012, https://alannalockward.wordpress.com/be-bop-2012-2014/ 
términos decoloniales el (arte) y la (estética) son puestos entre paréntesis. Ahora bien, los cambios en el contenido de la conversación son siempre internos a MCP. La novedad y el cambio son dos motores del progreso, modernidad, postmodernidad, desarrollo, post-desarrollo. El movimiento y transformación se manifiestan en la movilidad de la retórica de la modernidad que es siempre retórica de salvación, crecimiento y mejora. Y se manifiestan también en la cambiante lógica de la colonialidad: la legalización del fin de la esclavitud se promueve en pro de los valores humanos (retórica de la modernidad) mientras que la razón es que la esclavitud es más costosa que el trabajo asalariado (lógica de la colonialidad). Los cambios (mantra de la modernidad) son siempre en el contenido de la conversación (la novedad, lo nuevo, lo más reciente, el último modelo) permiten asegurar la continuidad de la colonialidad y la manipulación aesthésica (el sentir, el desear, el querer) de la población. Es precisamente el dicho muy conocido: "que las cosas cambien para que sigan como están". Y así desde el siglo XVI hasta hoy en día, lo nuevo (desde el Nuevo Mundo) los cambios son controlados por la retórica de la modernidad/postmodernidad digitada en la MCP. Por eso, la tarea decolonial consiste en la quita y el reemplazo de los términos de la conversación: no cambios en la cronología del acontecer sino desplazamientos laterales y desprendimiento de las ilusiones que regulan la retórica de "los cambios".

En lo que concierne al arte y la estética, los cambios de los contenidos en la MCP se gestaron en la segunda mitad del siglo XVIII. En realidad, 1750 es un año de referencia para la renovación de los contenidos de la conversación en todas las dimensiones de la MCP. Ahora bien, si no tuviéramos una analítica de la MCP no podríamos identificar cuáles son los cambios y en qué dominios se gestaron y continúan su marcha, hasta hoy. En el siglo XVIII emergió la economía política, por ejemplo, que generó notables cambios en los contenidos de la conversación económica con respecto a los contenidos que guiaban la economía en Europa de 1500 a 1750. Surgió el concepto de religión y el estudio de las religiones, cuyas consecuencias fueron el desplazamiento de la teología cristiana (católica y protestante) que había guiado los contenidos de la conversación desde 1500 a 1750. Y deberíamos decir también que la emergencia misma de la MCP en el siglo XVI fue generada por cambios significativos en los contenidos de la conversación en la esfera de la cristiandad occidental (luego Europa) gestados en la Edad Media y el temprano renacimiento. "Arte" y "estética" fueron invenciones seculares del siglo XVIII, como así también la aparición del concepto de "literatura." Con ella nacieron las figuras del artista y del escritor (Viala, 1985) que desplazaron a las figuras del poeta y del letrado.

Volvamos ahora a los conceptos de arte de estética. Si perseguimos la etimología de la palabra "arte" (en occidente por supuesto, en sus raíces griegas y latinas, nada vamos a encontrar en China o en Persia o en los Mayas, Aztecas e Incas) antes de 1750, nos encontramos con que ars nos remite a la habilidad de una persona para hacer algo. Y también a la manera e instrumentalización del hacer. En ese sentido ars es la traducción latina del griego techné. Arte habría pasado a significar, en el latín, algo así como "habilidad en la técnica de hacer algo" (sea una máquina, una pintura, una tragedia, una mesa o unos panes bien tostados y sabrosos). Las conversaciones en torno a todo aquello que después de 1750 se constituyen en torno a la palabra y concepto de "arte" desplazan lo que antes de esa fecha (aproximada por cierto) se exploraba en el vocabulario de la "poética". No por supuesto en el sentido restricto de poesía/poema, sino en el más amplio de la habilidad para hacer cierto tipo de cosas. Poiesis refiere al hacer, (to make) lo que hace un zapatero o Sófocles. La cuestión son los criterios que distinguen la poiesis del zapatero de la poiesis de Sófocles. Para eso está la Poética, es decir, la regulación de las convenciones sobre distinto tipos de haceres. Mientras que poiesis es un concepto en el orden del hablar y vivir cotidiano, poética es un concepto de segundo orden que otorga a poiesis un nuevo estatuto.

Pues bien, a grandes rasgos (puesto que este es un tema de tesis) digamos lo siguiente: a partir de 1750 se desplaza poiesis y se introduce ars. Poiesis nombra el hacer. Ars nombra las técnicas del hacer y la habilidad del hacedor. Hasta ese momento "arte" significaba muchas cosas, entre ellas las "siete artes liberales (el trívium y el quadrivium); se empleaba también en el ámbito de la academia y para todo hacer en el que se requería cierta habilidad y ciertos principios. Pero en los procesos de secularización de todos los saberes teológicos y humanísticos del renacimiento, la habilidad para manejar una técnica para hacer algo que deviene "arte" necesita de la "estética." La estética es al arte lo que la poética a la poiesis. Ahora bien, en el momento en que se generan tales cambios en el contenido de las conversaciones, asentados sobre lo hecho y dicho desde el Renacimiento, es también el momento en el que se consolida la noción de "individuo" (Van Dülmen, 1997). Es así que poeta (en latín derivado del griego poete (que Borges tradujo en su célebre relato, "El hacedor") y sus derivaciones en las lenguas del Renacimiento 

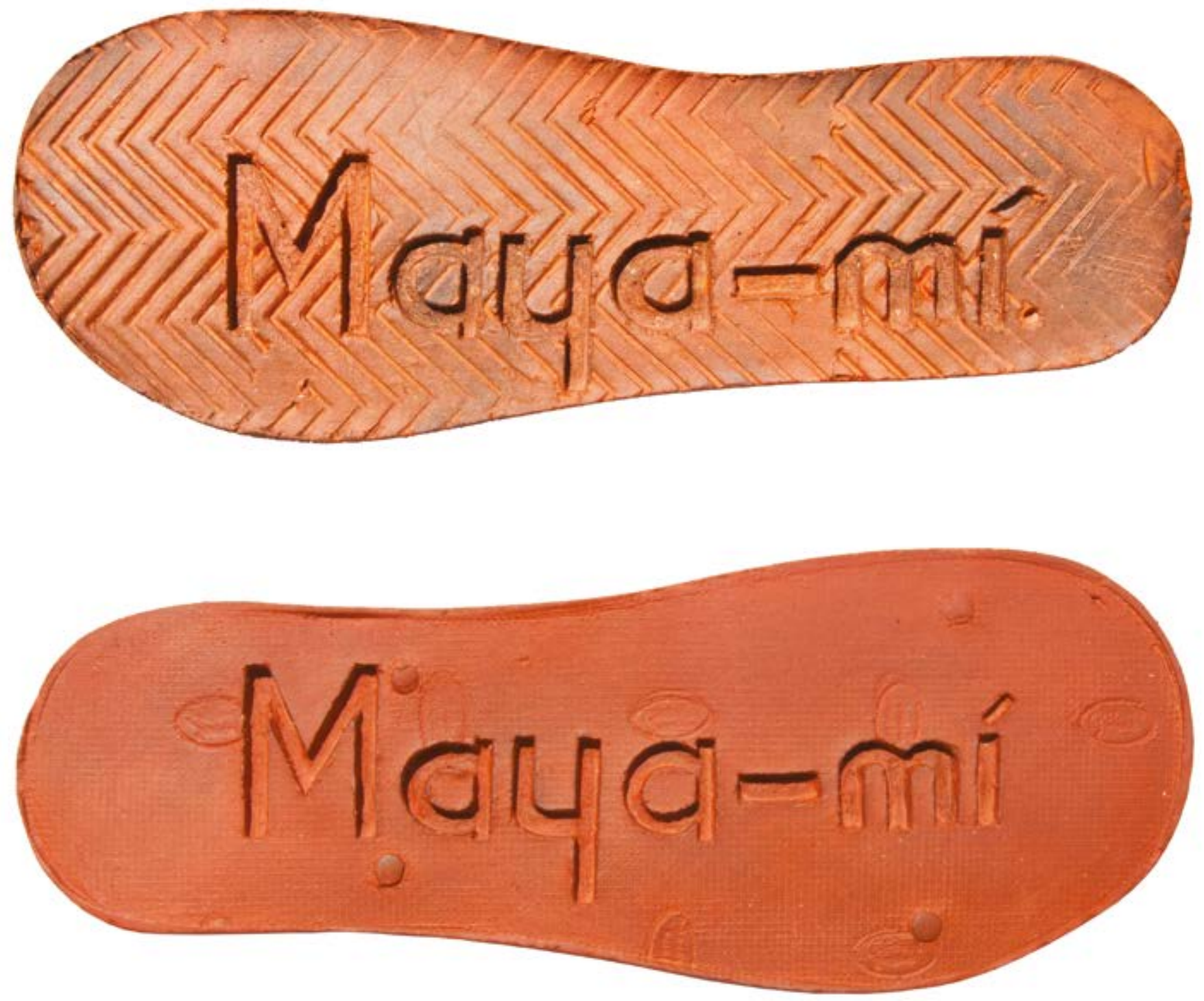

Imágenes 6 y 7. Maya-mi. Suela de chancletas de barro, en Miami, Estados Unidos. Benvenuto Chavajay (2013). 
europeo, deviene artista. Pero el artista ya no es una palabra que refiere a cualquier persona que hace algo: artista es quien hace arte enmarcado por la estética: es el individuo dotado de genio. La creatividad se localiza en determinadas personas que muestran, en su hacer, su habilidad creativa para hacer algo.

Las cuestiones con la que nos enfrentamos ahora son las que conciernen a la decolonialidad del arte y a la decolonialidad de la estética en los procesos de reconstitución epistemológica y estética.

\section{Decolonialidad: quita y reemplazo en los términos de la conversación}

Hemos mencionado varias veces y en variados lugares que fue Adolfo Albán Achinte quien por el 2001 o 2002 incorporó la reflexión decolonial en torno a la colonialidad del arte y de la estética. Preguntaba Adolfo, por ese entonces (en los cursos de doctorado dirigido por Catherine Walsh en la Universidad Andina Simón Bolívar -UASB-): ¿cuál es el lugar del arte y la estética en el patrón (o matriz decimos hoy también) colonial de poder? La pregunta se ancló finalmente en los cursos del doctorado en la UASB en julio-agosto del 2009. En ese curso, 7 de 25 participantes retomaron la pregunta que ocupó varias sesiones y presentaciones explorando el tema.

Quienes se interesaron en el tema fueron estudiantes de artes visuales y de sonoridades, historia y crítica de arte, filosofía. En ese momento, Pedro Pablo Gómez tuvo la idea de montar una exposición en Bogotá en torno a la estética y el arte en el patrón (o matriz) colonial de poder. La titulamos “Estéticas decoloniales en Abya Yala y la Gran Comarca".13

Con el título intentamos desprendernos de la hegemonía de la expresión tanto de la palabra "arte" como del marco "América Latina." Pusimos el acento en "estética", es decir, los discursos en torno a la palabra y el concepto de "arte" y en los nombres que indígenas y afro-descendientes le dieron a sus territorios. Así "América Latina" se reducía a su justo título (la América del Sur gobernada por eurodescendientes, contando por cierto variadas mezclas de sangre en la hegemonía de la cosmología europea). Fue una modesta intervención para reemplazar los términos de la conversación.

13 Ver, (Viala 1985).
Desde entonces el tema encarnó y tomó variadas formas y trayectorias. En este ensayo reflexiono sobre mi trayectoria personal en torno al tema y conecta, cuando sea relevante, con las contribuciones que se han ido sumando. Mi relato no es cronológico sino conceptual. Mire reflexión sobre el tema comenzó con el ensayo publicado en Calle 14 en marzo del 2010, "Aiesthesis decolonial". ${ }^{14}$ A poco de andar, las expresiones "decolonización de la estética", "estéticas decoloniales" y "Aiesthesis decolonial, "estéticas decoloniales" resultaban ambiguas. No estaba mal que lo fueran, pero si necesitábamos elaborar el desprendimiento y la reconstitución epistémico/estética. La tesis de Pedro Pablo Gómez, ahora publicada como libro, dio un paso más en la elaboración de estas categorías exploradas además en variadas formas de haceres: multimedia, cine, estatuas vivientes precedidas por un capítulo de elaboración conceptual. ${ }^{15}$

Y ¿qué de la palabra y concepto "arte"? ¿Qué tiene que ver con la estética? Que la palabra y el concepto "arte" no son palabras y conceptos decoloniales (como lo es la palabra y concepto colonialidad) era obvio entonces pero insuficiente. Lo importante fue el momento inicial en el que cualquiera de los vocablos, aún en su ambigüedad, ancló el sentir que se tradujo inmediatamente en el pensar. El vocabulario del que disponíamos no era nuestro, pertenecía a otro ámbito conversacional: construido por la retórica de la modernidad/postmodernidad. ${ }^{16}$ Este era el problema para el que necesitábamos el cómo. Cómo enfrentarnos decolonialmente con esta situación fue la segunda etapa de la pregunta inicial que, paradójicamente, ya empezaba a ser una respuesta. Habíamos deslindado las esferas de la modernidad/colonialidad por un lado y la decolonialidad por otro. Al hacerlo surgieron distinciones importantes:

- Colonialidad es un concepto decolonial que surgió en el límite de la transformación, en el cierre de la Guerra

$14 \quad$ Ver nota 7 arriba. En estos años varios artículos fueron publi-
cados en Calle 14. Revista de Investigación en el campo del arte,
entre 2010 y 2012. Ver especialmente, el volumen Arte y decolonia-
lidad (2011), 5(6), http://revistas.udistrital.edu.co/ojs/index.php/c14/
issue/view/261
$15 \quad$ Ver, Gómez, P.P. (2015). Estéticas fronterizas: Diferencia
colonial y opción estética decolonial. Bogotá: Universidad Distrital
Francisco Caldas. Calle 14, "Aesthesis decolonial y los tiempos relacio-
nales. Entrevista a Rolando Vázquez." (2016), 11(18).
$16 \quad$ Estas tesis han sido expuestas en Walter D Mignolo (2010).
Desobediencia epistémica. Retórica de la modernidad, lógica de la
colonialidad y gramática de la decolonialidad. Buenos Aires: Ediciones
del Signo.


Fría y la desintegración del Bloque Soviético, del Tercer Mundo en el Sur global;

- Modernidad es un concepto auto-reflexivo eurocentrado (e.g., centrado en la historia local, mentalidad y maneras de sentir y vivir de la Europa Occidental, originariamente Cristiandad occidental);

- Modernidad/colonialidad es un concepto decolonial implícito el artículo fundacional de Aníbal Quijano y explícito desde 1998 cuando comenzó a configurarse el proyecto derivado de Quijano.

Estas observaciones nos encaminan en dos direcciones: una es práxico-analítica y conceptual (diagnosis). También es analítica y conceptual la praxis que nos embarga en los detalles de la formación, transformación y gestación del patrón/matriz colonial de poder (MCP). La razón de la analítica es simple: si no sabemos/comprendemos qué es lo que nos atrapa y cómo nos atrapa (CMP) mal podríamos desprendernos porque no sabríamos de qué desprendernos. La cuestión no es tanto el cómo sino de qué. Si no sabemos de qué desprendernos poco nos hace falta el cómo. Si no tenemos una pregunta o un problema de poco nos sirve el método. La otra es práxico-proyectiva (prognosis). Opera en el desprendimiento y en la re-generación, resurgencia, re-existencia. Esto es, en la reconstitución epistemológica-estética, lo cual equivale a la decolonización del pensar (gnoseología) y la subjetividad (aesthesis). Pero ya el arte ligado a la estética moderno/colonial oculta la aesthesis que se expande en todos los órdenes de la praxis del vivir, pensar y el conocimiento científico/académico. La gnoselogía, decolonialmente argumentada, incluye la epistemología y la estética, dos modos regionales del conocer. Descartes y luego la modernidad/racionalidad (en la fórmula de Quijano), bloqueó lo aesthésico con lo racional. Las críticas postmodernas a la modernidad son críticas de contenido que no desplazan ni reemplazan los términos de la conversación. Las críticas postmodernas a la modernidad y al antropocentrismo son rencillas entre los miembros de las mismas familias.

Por eso lo decolonial aesthésico no consiste en describir, interpretar, hablar de "arte decolonial" o de los y las "artistas decoloniales" ni ya tampoco de "estética decolonial" sino que son nuestros (los organismos auto-llamados humanos) decires en todos los ámbitos disciplinario y vivenciales donde lo aestésico tiene su morada. Lo aesthésico (concepto decolonial) alimenta lo epistémico y lo estético (conceptos moderno/coloniales). Al decir lo que estoy diciendo no estoy "teorizando" lo aesthésico sino por el contrario, lo que usted está leyendo, es lo aesthésico en este momento que nutre mi razonamiento gnoseológico puesto que el razonar (como el emocionar) no es privilegio de ninguna disciplina y menos de la modernidad occidental. El razonar epistemológico es un sector muy delimitado del razonar.

\section{Coda}

La aparición del concepto colonialidad desenmascaró el lado más oscuro de los relatos y las promesas en nombre de la modernidad, el progreso, la civilización, la salvación, el desarrollo, la democracia, la epistemología, el arte y estética. Al hacerlo mostró la necesidad, la urgencia mejor, de desprendernos del imaginario moderno/colonial en todos sus órdenes. Al desprendimiento sigue la reconstitución epistémico/estética. En este ensayo, argumenté que la reconstitución epistémica/estética requieren conceptos y modos de razonar de quita y reemplazo en los términos de la conversación (la enunciación que controla los dominios de la MCP) no solo "cambios" en el contenido. De ahí que el desprendimiento lo sea de los términos de la conversación establecidos (y universalizados) en y por la retórica de la modernidad y no de sus contenidos.

Puesto que, sin la quita y reemplazo de los términos de la conversación, quedamos prisioneros de la enunciación que controla la retórica de la modernidad y lógica de la colonialidad. Es decir, quedamos atrapados en la MCP. La reconstitución epistémico/estética exige el vuelco en la geografía del razonar y una conceptualización desobediente del vocabulario hegemónico de la epistemología y de la estética. El vocabulario que aquí elaboro (gnoseología decolonial y aesthesis decolonial), responden a las necesidades del desprendimiento aestésico (lo que se siente) y gnoseológico (el razonamiento transversal, fronterizo y desprendido de la canonización moderno/ colonial de la epistemología y la estética.

En últimas, cambiar los términos de la conversación y las reglas del juego implica construir locus enunciationis desobedientes de las reglas del juego y del vocabulario de la enunciación moderno/colonial, instancia en la cual se manejan y gestionan los contenidos de la MCP. No se trata sólo de cambiar las palabras sino de la construcción de espacios diferenciales de enunciación anclados en la tierra de los cuerpos que habitan y (se) enuncian en la frontera. ${ }^{17}$

\footnotetext{
17 Este énfasis aclaratorio surgió del intercambio de correos que mantuvimos con Pedro Pablo Gómez durante la revisión del argumento, por lo cual le quedo agradecido.
} 


\section{Referencias}

Anzaldúa, G. (1987). Borderland/La Frontera. The New Mestiza. San Francisco: Aunt Lute, Books.

Cabnal, L. (2016). Red de sanadoras ancestrales.

Disponible en «https://luchadoras.mx/

lorena-cabnal-sanacion/»

Chavajay, B. (2015). Muxu'x. Of Origen and

Disobedience. [Exposición-catálogo]. Quetzaltenango:

Ciudad de la Imaginación.

Facundo Giuliano, F. (2019). Los no europeos, ¿podemos pensar? (Ed.) Buenos Aires: Ediciones del Signo (en prensa).

Ferrater Mora, J. (1984). Diccionario de filosofía. Vol. II. Madrid: Alianza.

Godoy-Anativia, M. (octubre, 2013). Desobediencia Visual: Una entrevista con Benvenuto Chavajay

y Kencey Cornejo. E-misférica 11.1, en «http://hemisphericinstitute.org/hemi/en/ emisferica-111-decolonial-gesture/cornejochavajay»

Gómez, P. P. (2016). HD: haceres decoloniales: prácticas liberadoras del estar el sentir y el creer. Bogotá:

Editorial UD.

(2015). Estéticas fronterizas: Diferencia colonial y opción estética decolonial. Bogotá: Universidad Distrital Francisco Caldas.

Gómez, P.P., y Mignolo, W. (2012). (Eds.). Estéticas decoloniales. Bogotá: Universidad Distrital Francisco José de Caldas.

Mignolo, W. (2003) Historias locales/diseños globales. Colonialidad, conocimientos subalternos y pensamiento fronterizo. Madrid: Ediciones Akal.

(2010). Aiesthesis decolonial. Calle14: Revista de investigación en el campo del arte, (enero-junio), 4(4), pp. 10-25.

(2010). Desobediencia epistémica. Retórica de la modernidad, lógica de la colonialidad y gramática de la decolonialidad. Buenos Aires: Ediciones del Signo.
González Vasquez, A., Ferreira Zacarias, G., \& Gómez, P. (2016). "Estética(s) decolonial(es)": entrevista a Pedro Pablo Gómez. Estudios Artísticos, 2(2), 120-131. doi:https://doi.org/10.14483/25009311.11531

Mignolo, W., y Gómez. P.P. (2012). (Eds.). Estéticas y opción decolonial. Bogotá: Universidad Distrital Francisco José de Caldas.

Mudimbe, V.Y. (1988). The Invention of Africa. Gnosis, Philosophy and the Order of Knowledge. Bloomington: Indiana University Press.

Quijano, A. (1992). Colonialidad y Modernidad/ Racionalidad. Perú Indígena, 13(29), pp. 11-20.

Quijano, A. (2015). Colonialidad del poder y clasificación social. Journal of World-System Research, 6(2), pp. 342-384. https://doi.org/10.5195/JWSR.2000.228

Sanjinés, J. (2005). El espejismo del mestizaje. La Paz: IFEA. https://doi.org/10.4000/books.ifea.4887

Santiago, K. (mayo, 2018). Lorena Cabnal, Sanación, feminismo y defensa comunitaria. En Luchadoras. Disponible en «https://luchadoras.mx/ lorena-cabnal-sanacion/»

Van Dülmen, R. (1997). El descubrimiento del individuo. 1500-1800. [1997]. Jesús Alborés (Trad.). Madrid: Siglo XXI.

Vázquez, R. (2016). Aesthésis Decolonial y los Tiempos Relacionales. [Entrevista]. Calle 14. Revista de Investigación en el campo del arte, 11(18), pp.76-93.

Viala, A. (1985). La naissance de l'écrivan. Sociologie de la littérature classique. Paris: Editions de Minuit.

Voegelin, E. (1968). Science, Politics and Gnosticism. Wilmington: IS Books.

VV AA. Arte y decolonialidad (2011), 5(/6). Disponible en «http://revistas.udistrital.edu.co/ojs/index.php/c14/ issue/view/261» 